\title{
GUIDE
}

To

\section{PRACTICAL WORK}

IN

\section{ELEMENTARY ENTOMOLOGY,}

$A N$ OUTLINE

FOR THE USE OF STUDENTS IN THE ENTOMOLOGICAL LAB

ORATORY OF CORNELL UNIVERSITY.

BY

Professor J. HENRY COMSTOCK.

ITHACA, NEW YORK.

Stereotyped and Printed at the University Press. $\mathrm{r} 882$. 
NATIONAL LIBRARY OF MEDICINE Bethesda, Maryland

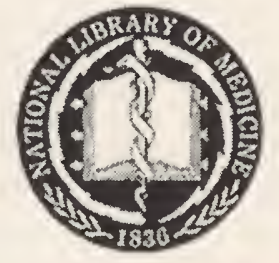




\section{GUIDE}

TO

\section{PRACTICAL WORK}

IN

\section{ELEMENTARY ENTOMOLOGY,}

$A N$ OUTLINE

FOR THE USE OF STUDENTS IN THE ENTOMOLOGICAL LAB. ORATORY OF CORNELL UNIVERSTTY.

BY

Professor J. HENRY COMSTOCK.

ITHACA, NEW YORK.

Stereotyped and Printed at the University Press.

r 882 . 



\section{PREFACE.}

ONE-FOURTH of the time assigned to Entomology in the courses in which it is a required study in this University is devoted to lectures. In these lectures the more general questions and the greater number of the facts which it is deemed desirable to give the students are discussed. The remaining three-fourths of the time is devoted to work in the laboratory and in the field. In this part of the course it is my desire that the students shall learn how to study Entomology. No effort is made to teach the student facts merely as facts; but it is hoped that each one will learn how to ascertain for himself the truths of Nature.

Owing to the limited time which the majority of students can give to Entomology, it is impracticable, even if it were desirable, to follow the so-called Agassiz method; by which a student is at first given a specimen and required to ascertain all that he possibly can, unaided, respecting it. I have in the beginning of the course, after an exposition of the nomenclature used, followed the method adopted by Huxley and Martin in their Elementary Biology. Later, after the student has acquired a knowledge of the terms used in Entomology and of the methods of investigation, subjects are assigned which he is expected to investigate with the minimum of assistance.

ITHACA, N. Y., Dec. 188x.

J. HENRY COMSTOCK. 


\section{INTRODUCTION.}

Practical work in Entomology consists of the making and recording of observations respecting insects, and the study of the records of observations made by others.

In order to describe insects intelligently or to understand the descriptions of them written by others, it is necessary to know the names applied by naturalists to the different parts of insects, and the terms by which the position and direction of these parts are indicated. For this reason Part I of this course is devoted to Anatomical Nomenclature. In Chapter I a set of terms by which the position and direction of parts may be designated is discussed. In subsequent chapters the names by which the parts of insects are known are defined and illustrated by reference to specimens which the student is supposed to be studying. Part II of the course is devoted to the details of the methods of Entomological investigations. 


\section{P A R T I.}

\section{CHAPTER I.}

TERMS DENOTING POSITION AND DIRECTION OF PARTS.

(§ r.) Need of a more exact nomenclature.-The use of the terms upper, lower, inner, outer, before, behind, anterior, posterior, and similar expressions in the technical descriptions of animals or of their parts, has led to much ambiguity. A great part of the confusion has doubtless arisen from the fact that very many of the early naturalists were physicians ; and they attempted in their descriptions of lower animals to avail themselves of the same terms that were in use in human anatomy. But as the natural position of man differs from that of the lower animals, in being erect, these terms in one case have a different signification from what they have in the other. For example, when applied to man, before means in the direction indicated by a line drawn from the center of the body to the ventral surface; in the lower animals it means in the direction indicated by a line drawn from the center of the body to the head. The same difficulty attends the use of the term anterior; and of the opposite of these terms. behind and posterior.

There is another source of confusion in the use of this class of terms. It is the fact that they are very commonly applied with reference to the plane of the horizon. Thus above means towards the zenith; below, towards the nadir;-and before and 
behind indicate directions parallel to the plane of the horizon. And thus whenever the position of an object is changed the terms denoting the relation of parts must be changed. An example illustrating this is given in $\S 7$.

\section{(§2.) Proposed improvements in nomenclature.-} From time to time efforts have been made to establish a more exact nomenclature for the purpose of designating the position and direction of parts of animals. ${ }^{1}$ But as yet no system has been generally adopted. For several years Professors Wilder and Gage have been earnestly endeavoring to perfect a system which, while it should involve the minimum of change in the nomenclature now in use, should include, "So far as practicable, only such terms as are brief, simple, exact, significant, of classical origin, and capable of inflection." And which should thus facilitate the recognition of parts by students, lessen the labor of memorizing, abridge the length of descriptions and at the same time increase their accuracy.

The result of their labors is a system which embodies the best features of the previously proposed systems, and makes a notable advance in the field of terminology.

In the preparation of this outline I have adopted such parts of this nomenclature as are applicable to entomology. I will therefore explain the principal features of it. ${ }^{2}$

The names of the various parts and appendages of the body of an insect will be given in subsequent chapters of this work. Here we have only to deal with terms denoting position or direction of parts.

1 The most important of the earlier efforts was made by Dr. John Barclay, the anatomical preceptor of Professor Owen, who published in 1803 a volume of nearly two hundred pages, entitled A Neru Anatomical Nomenclature Relating to the Terms which are expressive of Position and Aspect in the A nimal System.

For the titles of other papers on this subject see the work cited in the next note.

2 I shall define only the terms which I have found necessary in the preparation of this cutline; and shall define these as briefly as possible. For a fuller discussion of the subject, the student in leicired to the "Guide to Practical Work in Elementary Anatomy, Histology and Experimental Physiology," by Professors Wilder and Gage.

It will be seen that the method which I have adopted to explain these terms differs slightly from that of Wilder and Gage, but the results obtained are the same. 
These terms naturally fall under three heads: nouns, adjectives and adverbs.

(§ 3.) Nouns.- - In this place it is necessary to define only three nouns, the second and third of which are derived from the first; these are meson, dorsimeson, and ventrimeson. ${ }^{1}$

Meson, Dorsimeson, and ventrimeson.-Frequently the position or direction of parts is referred to an imaginary plane dividing the body into approximately equal right and left haives. This middle plane is called the meson ( $\tau$ ó $\mu \varepsilon$ $\sigma o \nu$, the middle). ${ }^{2}$

If it is necessary to refer to the lines constituting the dorsal and ventral borders of the meson, these are designated as the dorsimeson and ventrimeson respectively. ${ }^{3}$

EXAMPLE. - The wing covers of a beetle meet without overlapping on the dorsimeson.

(§ 4.) Adjectives.-The adjectives will be defined later; they end in $a l$.

Examples. - Dorsal, ventral, mesal.

Note. - Cephalic and intermediate are exceptions to this rule.

(§ 5.) Adverbs.-The adverbs are formed by substituting for the adjective ending the letters $a d$, the Latin equivalent of the English ward. ${ }^{4}$

Examples.-From the adjectives dorsal, ventral, and mesal are formed the adverbs dorsad, ventrad and mesad. Thus a part which extends towards the meson is said to extend mesad.

(§6.) Compound words.-In forming compound words indicating direction, the vowel $o$ is substituted for the termination of the first member of the compound.

EXAMPLES.-Dorso-ventral, eaudo-eephalie, dextro-sinistral.

(§ 7.) Points to which the position and direction of parts may be referred (dorsal, ventral, ceplatic, cautal,

1 First proposed by Wilder, (Science Vol. II, D. 124); meson is, however, the equivalent of mesion, which was proposed by Barclay (l. c. page 12I), but does not appear to have been adopted by any subsequent writer.

2 Other body planes have been suggested to which to refer the position and direction of parts; but as the meson is the only one which exists in nature (in other words, the only one respecting the position of which there can be no doubt) and as the other planes are not really necessary, I shall omit any discussion of them.

${ }^{3}$ Respecting the propriety of the use of dorsimeson and ventrimeson and other hybrid words see Wilder and Gage l. c. page 28.

- This was first proposed by Barclay l. c. page 165 . 
dextral and sinistral; and dorsad, ventrad, etc.).-There are six points to which the position and direction of parts are very commonly referred. These cardinal points may be indicated with more or less circumlocution by the use of popular terms. Take for example a grasshopper and place it in its natural attitude ${ }^{1}$ on a table. You may now describe the relative positions of the different parts of the insect as compared with any given part by the use of the terms right, left, above, below, before and behind; these six terms indicating six well understood directions.

To the terms right and left there are no objections, excepting that they pertain to our language alone, and can not be inflected. The other terms, however, are insufficient.

Place the grasshopper on its back on the table. Now the description of the relation of parts which was just made is not true; for what was above is now below, and what was below is now above.

Stand the grasshopper on its head. Again the description must be changed; for what was behind is now above, and what was before is now below.

Evidently some of these terms are inadequate for scientific purposes. Right and left are definite; but not so the terms commonly used to indicate the four other cardinal directions. There are, however, four adjectives which are in use for this purpose, which are definite, always meaning the same thing whatever may be the relation of the animal described to anything else in Nature, and which, from their derivation, can be understood at a glance. These are dorsal, ventral, ${ }^{2}$ cephalic, and caudal. If to these we add dextral and sinistral, the Latin equivalents of right and left, we have for designating the six cardinal directions six terms which are "Brief, simple, exact, significant, of classical origin, and capable of inflection."

\footnotetext{
1 So that its ventral surface will be nearest the earth, and parallel to the plane of the horizon.

2 "Should the alleged correspondence of the ventral region of the Vertebrate with the tergal region of the Arthropod prove to be one of true homology, it may be desirable in time to discard dorsal and ventral for more suitable terms; but for the present, if on practical grounds alone, it seems well to retain them." Wilder and Gage l. c. p. 24.
} 
The adverbial forms of these six terms are: dorsad, ventrad, cephalad, caudad, dextrad, and sinistrad.

It is important here to more definitely define the directions indicated by these six sets of terms.

When we say that a certain part extends dextrad, we do not mean necessarily that it extends towards the right side of the animal or even toward a plane tangent to the right side of the animal; but that it extends towards a point which is in a certain well understood direction ${ }^{1}$ and which is at an infinite distance in that direction. We are thus able to indicate the position of an object which may be far exterior to the body of the animal with whose position we are comparing it. This is perfectly in accordance with the popular use of the terms right and left.

According to this definition, all lines extending right and left across the body of an animal are parallel.

The same may be said respecting ventro-dorsal lines. Dorsad being equivalent to behind in the sense in which it is applied to the body of man, or above as applied to the body of a quadruped when in its normal position.

It is also true that all caudo-cephalic lines are parallel. This is a point to which careful attention must be paid, else there is liability to error. It is quite natural to think that cephalad means towards the head or towards the head end of the body axis; and that caudad means towards the tail. The fact is that cephalad means towards a point which is in a direction indicated by a line drawn from the center of the animal to the head, but at an infnite distance in that direction. In other words, these terms must be used in a way analogous to that in which we use right and left.

Exampies. - Take a figure of a Dragon-fly with its wings extended as when at rest. Draw a line from the distal extremity of one of the wings to the hearl. Although this line extends directly towards the head it does not extend cephalad; but more or less nearly mesad. A line extending cephalad from the distal extremity of a wing (or from any other part) is parallel to the cephalo-caudal axis of the body.

1 Indicated by a line drawn at right angles to the cephalo-caudal and dorso-ventral axes and towards the right side. 
(§ 8.) Differences between the technical and popular uses of cephalic and caudal.-It has just been shown that in the use of these terms it is not the head and tail to which the position and direction of parts are referred, but to two of the cardinal directions which are at right angles to right and left. Thus when an insect extends its antennae cephalad, the most cephalic segments of these organs are those farthest from the head. For the same reason we can speak of the caudal part of the head or of the cephalic portion of the tail. It will be seen that this does not accord with the popular use of these terms (as defined in the dictionaries) according to which no part of the body is cephalic except the head; and of the different parts of the head one is just as much cephalic as another.

(§ 9.) Oblique lines.-The position or direction of a part towards a point between two of the cardinal points, or toward a point between one of the cardinal points and a line connecting two other cardinal points can be designated by a compound term.

ExAMpLEs. $-\Lambda$ part which extends in a direction between those direc. tions which are indicated by dextrad and caudad is said to extend dextrocaudad. A part which extends in a direction between those directions which are indicated by dorsad and dextro-caudad is said to cxtend dorsodextro-candad. This last direction would be indicated in popular terms by saying: Towards the back and to the right and towards the tail.

(§ Io.) Lateral and Laterad.-In the descriptions of bi-laterally symmetrical animals, like insects, it is frequently desirable to speak of a part or parts as being dextrad or sinistrad without specifying either. For this purpose the term lateral is used; the corresponding adverb is laterad.

Examplis. - The wings are lateral appendages of the body; and in the Dragon-fly they extend laterad when the insect is at rest.

(§ II.) Ectal, ectad, ental, and entad. ${ }^{1}$ - It is often necessary, especially in the study of internal anatomy, to compare parts with relation to their nearness to or remoteness from the surface of the body. For this purpose the terms ectal ( $\dot{x} x \tau$ ós,

1 These terms were first proposed by Wilder, Science Vol. I1, I). 124 . 
outside) and ental ( $\dot{\varepsilon} v \tau 05$, within) are used. The adverbial forms of these terms are ectad and entad.

EXAMPLEs. - The principal muscles of an insect are attached to the ental surface of the body wall, or to parts of the body wall which project entad.

( $\S$ I2.) Aspects of the body.-In describing animals it is often desirable to specify that part of the body which looks in a certain direction. For this purpose the term aspect is used combined with an adjective indicating the direction in which the surface in question looks.

Exasples.-Dorsal aspect, ventral aspect.

Six aspects of the body are recognized; these are the two lateral, (dextral and sinistral), dorsal, ventral, cephalic, and caudal. ${ }^{1}$ 'The fact that the outlines of the body of an animal are more or less curved does not interfere with the practical application of the above terms.

(§ 13.) Proximal, distal, proximad and distad.-In describing appendages of the body (legs, wings, etc.) the position of parts may be referred to the two ends of the appendage by use of the terms proximal and distal. Proximal indicates nearness to the end of the appendage which is attached to the body; distal, to the end which is free. From these adjectives the adverbs proximad (towards the proximal end) and distad (towards the distal end) are formed.

EXAMPI.ES. - The proximal segment of the leg of an insect is the coxa. The segments of the leg distad of the tibia constitute the tarsus.

( $\S$ 14.) Aspects of appendages. - In addition to the two ends of an appendage four aspects are recognized. To these the same terms are applied as to the corresponding aspects of the body : viz., clorsal, ventral, cephalic, and caudal. It is therefore necessary to have a rule by which the correspondence between the aspects of the body and of appendages can be determined. In other words, a definite position must be chosen as the normal position of an appendage. Naturalists are quite well agreed as

1 Cases may occur where it will be desirable to speak of an aspect which looks in a direction bctween two of the cardinal dircctions. I see no reason why this should not be done. Thus we may speak of the lines or spots on the latero-dorsal aspect of a larva. 
to what is the normal position of the limbs of the Vertebrates. ${ }^{1}$ The following are what I believe to be the analogous positions for the legs and wings of insects. ${ }^{2}$

(I.) Wings.-Extended horizontally at right angles to the body as are the wings of a Dragon-fly (Libellula) when at rest.

(2.) Legs.-Extended horizontally at right angles to the body so that the convexity of the articulation between the two principal segments of the leg (femur and tibia) shall look dorsad; and so that the surface of the tarsus ("foot") which is usually applied to the ground when walking shall look ventrad.

The dorsal, ventral, cephalic, or caudal aspect of a wing or leg is that aspect which, when the wing or leg is in its normal position, looks in the same direction as does the aspect of the body which bears the same name ( $\S$ r 3 ).

( $\$$ r.) First, second, third, etc. - When the individuals of a series of parts forming a portion or the whole of the body are indicated by the terms first, second, third, etc., the cephalic member of the series is the first.

EXAMpLE. - The first abdominal segment is the one nearest the head.

When the series forms a part or the whole of an appendage of the body, the first member of that series is the proximal one.

EXAMPLE.-The first segment of a leg is the one which is articulated to the body.

The direction of an appendage does not modify the above rule.

EXAMPLE. - The first segment of an antenna is the one which is articulated with the head; notwithstanding that when the antennae are directed cephalad as is usually the case this segment is the one nearest the caudal end of the body.

(§ r6.) Intermediate.-In order to avoid ambiguity the word mesal and its derivatives are used only with reference to the meson. The second member of a series of three similar parts is designated as the intermediate.

I See Wilder and Gage, Guide p. 37.

2 The necessity for referring to the aspects of other appendages than the legs and wings will so seldom arise that it does not seem worth while to attempt to determine the normal positions of such appendages. 
(§ I 7.) Normal position of the body.-The greatest difficulty in the application of this nomenclature, or, in fact, of any system for designating the position and direction of parts of the body arises from the fact that frequently the cephalo-caudal axis of the body is not a straight line. In the majority of larvae and adult insects the mouth is undoubtedly at the cephalic end of the body. This then must be considered the normal position of the mouth. But in some insects the head is bent so that the mouth is not so far from the caudal end of the body as are other parts of the head. Take for example a Homopterous insect, as a Cicada. Here the mouth parts apparently project caudad from the ventro-caudal part of the head. In the next chapter it will ${ }^{\circ}$ be shown that a certain part called the gula, which in most insects forms the ventral wall of the head, in the grasshopper, apparently forms the caudal wall; the head of that insect being bent so that the mouth is directed towards the object upon which the insect is standing, i. e. at an angle of $90^{\circ}$ to the normal position; and thus the part that is normally ventral becomes apparently caudal.

The question arises, how shall such parts be described? In their natural attitude or in their normal position ? ${ }^{1}$ To one who has given the matter careful thought it is evident that a system by which a cephalo-caudal line becomes ventro-dorsal whenever an animal bends its head ventrad will surely lead to confusion. The only alternative is to describe the parts in their normal position in preference to describing them in their natural attitude when the two differ.

It is, however, at times very difficult to decide what changes should be made to bring a distorted part into its normal position. To do this requires a considerable knowledge of the group of animals to which the species under observation belongs. Even

1 By the natural attitude of a part is meant the attitude which that part really has in the species in question; while by the nomal position of a part is meant the position which that part holds in what is considered the type of the class of animals to which the species in question belongs. Thus the normal position of the mouth of an insect is at the cephalic extremity of the body axis; but its natural attitude in a grasshopper or a Cicada is very different from thic. In other words: Normal implies relation to a type; while natural does not. 
then there may be different theories as to the changes which have occurred to bring about the distortion; and the choice of terms to be used will be decided by the theory which the describer holds respecting the distortion.

In cases of this kind where the part can not be readily imagined in its normal position it is necessary to state the natural attitude in order to avoid a chance of error. This should always be done in such a way that the reader can not make the mistake of supposing that it is the normal position that is given.

The most exact way is for the writer to first state what he believes to be the normal position, and then to state parenthetically - what is the natural attitude.

EXAMPLE.-On each side of the head of the Red-legged Locust there is a suture extending from the eye cephalad (apparently ventrad) to the base of the mandibles.

In some cases, where many distorted parts are to be described, and where the writer does not care to discuss the nature of the distortion, but simply to describe the position or direction of the parts as they are in the species under consideration, the description can be made much more concise and less liable to be confusing to a student by omitting the terms expressing the normal position or direction of the parts.

In such cases I have used with the term denoting the natural attitude the prefix pseudo.

ExAmple.-On each side of the head of the Red-legged Locust there is a suture extending from the eye psendo-ventrad to the base of the mandibles.

The student will note that the difficulties arising from differences in the normal positions and natural attitudes of parts are not peculiar to this nomenclature; but will beset any system which can be devised.

(§ I8.) Limitations to accuracy.-As the body of an animal presents but few plane surfaces or straight lines it is often impossible to describe the position or direction of a part with absolute accuracy. Practically, however, one will meet with but few serious difficulties. Thus in describing the direction of a curved or undulating line on the surface of the body it will rarely 
be necessary to do more than to give the general direction of that line; the reader will understand that it follows the sinuosities of the surface of the body.

\section{CHAPTER II.}

THE EXTERNAL ANATOMY OF A GRASSHOPPER.

(Caloptenus femur-rubrum Harris.)

(§ 19.) Grasshoppers are among the most common of insects; and, being comparatively large, they are very available for the purposes of study. Moreover, those portions of the body which are commonly called the external parts or hard parts are, as a rule, remarkably distinct in these insects. They are, therefore, very desirable subjects to use when a student is beginning his study of the external anatomy of insects. ${ }^{1}$

As the different species of grasshoppers vary considerably in the forms of their external parts, it is best to first study a particular species as a type; later it will be easy to compare other species of grasshoppers with this type, and to note the variations in their structure. And still later the grasshopper may be taken as a type of the class of insects ancl members of each of the different orders of insects may be compared with it.

If for any reason the student is unable to study the particular species described in this chapter, he can, with little care, trace out the parts described upon the body of any of the more common of the larger species of grasshoppers. In this case the student should note carefully all the particulars in which the species studied differs from the one described here. He can thus begin to acquire an idea of the characters which distinguish species and genera.

The idea of using a grasshopper for this purpose was suggested to me by an outline of the anatomy of a grasshopper prepared (not published) by Dr. Brooks several years ago for the use of a "Teachers' Class" in the Johns Hopkins University. 
The species which I have selected for study is the most common grasshopper of the Eastern United States. It occurs abundantly from the Great Lakes to the Gulf of Mexico and from the Atlantic to the foot of the Rocky Mountains. It may also be found in the far West, even on the Pacific coast; but it is less common there than in the East. The English name of this insect is the Red-legged Locust; its scientific name is Caloptenus femur-rubrum.

( $\$ 20$.$) If the student will go into the field in the Eastern$ United States during the summer or autumn and collect twenty or thirty grasshoppers, making no effort to select any particular kind, he will be almost certain to obtain several specimens of this species. After killing the insects thus collected, either by leaving them for a few minutes in alcohol or in a cyanide bottle, select from them those which are at least $x 8 \mathrm{~mm} .(3 / 4$ inch) in length and which do not exceed $25 \mathrm{~mm}$. ( $\mathrm{I}$ inch) in length. From these choose those which agree in the following particulars: "Grizzled with dirty olive and brown;" a black spot extending caudad from the eyes; a yellow line on each side of the body extending obliquely from the proximal end of the wings to the caudal leg; a row of dusky brown spots along the middle of the cephalic wings; and with the legs marked with red.

The specimens thus selected will be in all probability Caloptenus femur-mibrum.

( $\$ 2$ r.) If a sufficiently large series of specimens of the Redlegged Locust be examined, it may be seen that there are two kinds: one, in which the caudal part of the body tapers to the end, which bears four pointed and curved horny pieces; and another, in which the caudal part of the body increases in size caudad and is terminated by a single large hood-shaped plate. The former is the female; the latter, the male.

In studying the following outline of the external anatomy of C. femur-rubrum the student is expected to carefully verify or 
correct each statement made in the text, by an examination of specimens.

\section{DIVISION OF THIE BODY INTO REGIONS.}

(§ 22.) The body of a grasshopper is composed of a series of more or less ring-like segments. In the caudal part of the body the ring-like nature of the segments is obvious; in the cephalic part it is less so. These segments are grouped into three regions : head, thorax and abdomen.

(\$ 23.) Head. - The head is the first or cephalic of the three regions of the body. Apparently it consists of a single segment.

( 24.) Thorax.-The thorax is the second or intermediate region of the body. It is readily distinguished by its appendages; which are three pairs of legs and two pairs of wings. It consists of three segments; but as each segment is composed of several distinct pieces, it requires considerable study to trace the outlines of each segment. We will return to this subject later.

( $\$ 25$.$) Abdomen.-The abdomen is the third or caudal$ region of the body. The segments of which it is composed are more simple, distinct, and ring-like than those of the other. regions.

STRUCTURE OF THE BODY WALL.

(§26.) Chitine.-In studying the anatomy of insects it is found that in the adult state the greater portion of the body wall, that part of the insect which corresponds in position to the skin of higher animals, is hard.

This hardness is due to the deposition of a horny substance called chitine in the membrane which constitutes the body wall.

(§27.) Sclerites.-The chitine is not evenly distributed throughout this membrane. Pull the head of a grasshopper so as to separate it from the thorax as far as possible without breaking the insect. Note that the head is joined to the thorax by a soft flexible membrane, in which but little, if any, chitine has been deposited. 
Examine the sides of the thorax with a lens and observe that the body wall appears to be made up of many distinct pieces, like a mosaic. The integument is, however, really continuous; and in each case what appears as a distinct piece is simply a portion of the body wall in which considerable chitine has been deposited. Such a portion of the body wall is called a sclerite.

( $\$ 28$.) Sutures.-The sclerites constitute the greater part of the body wall, the soft membranous portions separating them being in most cases narrow. Usually these narrow portions are mere lines; they are then called sutures.

Frequently the sutures become entirely effaced. We are therefore often unable to distinguish certain sclerites in one species of insect which we know to exist in another.

In such cases the effaced suture is said to be obsolete.

\section{PARTS OF THE HEAD.}

(§ 29.) The principal portion of the chitinized parts of the head are firmly joined together so as to constitute a box which contains what may be called by analogy the brain of the insect and certain other important organs. To this are articulated a number of movable appendages. The parts of the head may be classed, therefore, under two divisions; first, the fixed parts; second, the movable parts.

\section{THE FIXED PARTS OF THE HEAD.}

( $\$ 30$.) Compound eyes.-The most striking in appearance of the fixed parts of the head are the eyes. These are two large nearly hemispherical objects; one on each side, forming a considerable portion of the latero-dorsal part of the head.

Place the grasshopper on a glass slip on the stage of a compound microscope and examine one of the eyes, using a one-half inch objective. Note the honey-comb-like structure of the eye. Each of the hexagonal divisions of the eye is a cornea of a distinct eye. These large eyes are therefore compound; and each of the

1 The sclerites are analogous to the centers of ossification in the bones of the higher animals. 
small eyes of which they are composed is termed an ocellus (plural ocelli).

Make a drawing showing the honey-comb-like structure of the cornea of a compound eye.

(\$ 3 r.) Simple eyes.-Pseudo-cephalad ${ }^{1}$ of the pseudodorsal half of each compound eye there is a small transparent hemispherical body. These are the simple eyes. There is a third simple eye situated in a depression near the center of the pseudocephalic aspect of the head. The simple eyes are usually termed ocelli; sometimes, stemmata (singular stemma.)

When the term ocelli is used in descriptive works, if there is nothing in the context to indicate the contrary, it is almost invariably applied to the simple eyes, and not to the elements of the compound eyes. In the same way the term eyes usually refers to the compound eyes unless otherwise indicated by the context.

(§ 32.) Epicranium.-The simple eyes are situated in, and the compound eyes surrounded by a large sclerite which constitutes the greater portion of the fixed parts of the head or cranial box. This sclerite is the epicranium. The cephalic and lateral parts of the epicranium are separated on each side by a suture which extends pseudo-rentrad from the eye. The pseudoventral ends of these sutures are joined by a very prominent suture which forms the cephalic (pseudo-ventral) boundary of the cephalic portion of the epicranium.

Remove the head from the thorax and mount it on a slender pin, inserting the pin in the center of the pseudo-cephalic aspect of the head. The pin will now serve as a handle.

Note the slightly elevated narrow ridge which separates the lateral from the pseudo-caudal aspect of the head. This ridge marks the position of the suture which constitutes the pseudocaudal border of the epicranium. Upon the dorsal aspect of the head this suture is obsolete.

1 Note that the mouth of the grasshopper is directed ventrad; consequently the natural attitude and direction of a part of the head do not correspond with the normal position. See $\S$.7. 
Upon each side joining the pseudo-ventral end of the suture just described and the pseudo-ventral end of the one which extends pseudo-ventrad from the compound eye is a well marked suture, which forms the pseudo-ventral border of the lateral part of the epicranium.

(a.) Vertex.-The pseudo-dorsal part of the epicranium is called the vertex.

(b.) Front.-That part of the epicranium which is upon the pseudo-cephalic aspect of the head is termed the front.

(c.) Genae.-The lateral parts of the epicranium are known as the genae or cheeks. ${ }^{1}$

(§ 33.) Occiput.-Examine again the narrow ridge which separates the lateral from the pseudo-caudal aspect of the head, and forms the pseudo-caudal border of the epicranium. Note that it may be easily traced on each side through the broad black stripe which extends caudad from the eye; and that dorsad of that stripe it is obsolete. On each side of the head from a point on this ridge a short distance pseudo-ventrad of the black stripe a suture extends across the caudal aspect of the head to the membrane connecting the head with the thorax. This suture constitutes the ventral border of the sclerite which forms the caudal part of the dorsal portion of the fixed parts of the head. This sclerite is the occiput. As already indicated, the suture between the occiput and the epicranium is well marked on the lateral aspects of the head; but on the dorsal aspect it is obsolete. Hence on this aspect there is no indication of the line where the occiput ends and the epicranium begins. ${ }^{2}$

(§ 34.) Gula.-Ventrad of the occiput and pseudo-caudad of the genae is a large sclerite which forms the chief portion of the pseudo-caudal aspect of the fixed parts of the head. This is the gula.

1 There is upon each gena a depressed line which appcars like a suture but is not one.

2 If the student finds it difficult to trace the sutures described herc, he should boil the head of the grasshopper in a solution of caustic potash. This will destroy the soft parts and bleach the walls of the head so that the sutures may be easily traced. 
The gula and occiput form the boundary of the large opening which connects the cavity of the head with that of the thorax. The gula is separated from the epicranium by the narrow ridge described above.

The mesal part of the gula is not visible without dissection. Carefully remove the appendages of the pseudo-ventral part of the pseudo-caudal aspect of the head. This may be done by lightly scraping the gula with a knife. It will be seen that the lateral portions of the gula are connected by a strong part extending from sicle to side.

Make a drawing of the pseudo-caudal aspect of the head just prepared; and name the parts.

( $\$ 35$.$) Clypeus.-Examine again the pseudo-ventral border$ of that part of the epicranium which is upon the pseudo-cephalic aspect of the head. Note that the prominent suture bounding this part separates it from a very broad, but short, and somewhat T-shaped sclerite. "This is the clypeus.

Although in a grasshopper the clypeus appears like the basal segment of an appendage of the head; from its form and position in other insects it is classed with the fixed part of the head.

These are all of the fixed parts of the external crust of the head of a grasshopper.

Make a drawing of the pseudo-cephalic aspect of the head; and name the fixed parts.

(§ 36.) Review.-The fixed parts of the external crust of the head of a grasshopper consist of four sclerites; three of these, the occiput, the epicranium, and the clypous pertain to the dorsal (dorsal and pseudo-cephalic) part; and one, the gula, to the ventral (pseudo-caudal) part.

The epicranium consists of the vertex, the front and the genae.

THE MOVABLE PARTS OF THE HEAD.

(\$37.) Under this category are classed a pair of jointed appendages termed the antennae and the organs known collectively as the mouth parts. 
( $\$ 3^{8}$.) Antennae.-Just cephalad of each compound eye there is attached to the head a long, thread-like, many-jointed appendage. These are the antennae. Each antenna is situated in a depression which is known as the antennary fossa.

\section{Mouth Parts.}

(§ 39.) Labrum.-Articulated to the cephalic (pseudo-ventral) border of the clypeus is a broad frecly movable flap. This is the upper lip or labrum.

Letter this part in the drawing made under $\S 35$.

(§ 40.) Mandibles.-Carefully remove the labrum. By doing this there is exposed a pair of jaws which open by a mesolateral motion of each jaw. These are the mandibles. Each mandible consists of a single short and thick piece, the distal extremity of which is notched so as to form a series of teeth.

Remove the mandibles. This may be done by separating them with a pin and turning each one laterad until it breaks from the head.

Make a drawing of one mandible.

(§ 4r.) Maxillae.-By the removal of the mandibles there is exposed a second pair of jaws which, like the mandibles, open by a meso-lateral motion. These are the maxillar. Unlike the mandibles the maxillae are very complicated organs. We will return to them later. ( $(45$.)

( $\$ 42$.$) Labium.-Remove the head of the grasshopper and$ pin it with the caudal aspect uppermost to a piece of cork.

Note the freely movable flap which is the ventral (pseudocaudal) part of the mouth parts. This and the crescent shaped piece to which it is attached form the lower lip or labium.

The labium consists of the following parts :

Submentum.-The submentum is the proximal part of the labium. It is nearly crescent-shaped; and is joined to the membrane which connects the head with the thorax. ${ }^{1}$

1 When the parts of the head are in their normal position the submentum is articulated to the ecphalic border of the gula. The unusual position of the submentum in this and allied insects laas led some writers to mistake it in these cascs for the gula. 
Mentum.-This is the central portion of the labium; and is the principal part of that organ. It is articulated to the distal margin of the submentum. To the distal margin of the mentum are joined two movable flaps; and to each lateral margin is joined an organ consisting of three segments.

Labial Palpi.-These are the three-jointed organs of which one is joined to each lateral margin of the mentum.

Palpiger.-The labial palpi are not joined directly to the mentum. There is on each side of the mentum a sclerite which bears the palpus of that side and which is called the palpiger. The suture between the palpiger of each side and the mentum is almost obsolete. Its position is indicated by a slight groove which causes the palpiger to appear somewhat like a segment of the palpus.

Ligula.-This is the distal portion of the labium. It consists of two large movable flaps.

(\$ 43.) Hypopharynx.- If the specimen has become dry so as to be brittle, it should be softened with a little water.

With the specimen pinned as in last section, carefully lift the ligula so as to expose the maxillæ. Note the tongue-like organ which arises from the labium and from between the maxillæ. This is the Hypopharynx.

( $\$$ 44.) Remove the labium and place on a glass slip in a drop of Canada balsam or glycerine and cover with a cover glass. Examine with microscope using a three-fourths inch objective. Make drawing of ventral (pseudo-caudal) aspect of labium; and letter the parts.

Study the distal end of the distal segment of a labial palpus with a higher objective. Observe the tactile papillae with which it is furnished. Make drawing of this part.

(\$45.) Parts of the Maxillae (See § 4I).-After the removal of the labium it is easy to distinguish the maxillae, of which there is one on each side between the labium and the mandibles.

Remove a maxilla and mount it in Canada balsam or glycer. 
ine, with the pseudo-caudal aspect uppermost. Examine with microscope using a three-fourths inch objective.

Make drawing of a maxilla; and name the parts, which are as follows :

Cardo.-The cardo or hinge is the proximal segment of the maxilla. It is triangular in outline in this insect.

Stipes.-The stipes or footstalk is the second segment of the maxilla; it is the large quadrangular sclerite which forms the central part of the maxilla.

Lacinia.-Articulated to the distal end of the stipes is a large sclerite, which tapers distad, is curved, and is terminated by strong teeth. This is the part known as the lacinia.

Galea.-Joined to the distal end of the stipes pseudo-laterad of the lacinia is a part consisting of two segments. This is the galea. The distal segment of the galea is large, spoon-shaped and covers the inner lobe like a hood; the proximal segment is constricted in the middle so as to slightly resemble a dumb-bell in outline. The galea is also known as the outer lobe, upper lobe, or superior lobe.

Palpifer.-Joined to the pseudo-lateral border of the stipes and between the cardo and the proximal segment of the galea is a narrow sclerite; this is the palpifer. This part also resembles a dumb-bell in outline.

Maxillary Palpus.-Articulated to the distal end of the palpifer is a long slender organ consisting of five segments; this is the maxillary palpus.

After completing the drawing of the maxilla as a whole, study the distal end of the distal segment of the maxillary palpus with a higher objective, and make a drawing of this part.

( $\$ 46$.$) Review.-The mouth parts consist of an upper-lip,$ labrum; and under-lip, labium; two pairs of jaws acting laterally between these lips; and a tongue-like organ, hypopharynx. The dorsal pair of jaws is called the mandibles; the ventral pair, the maxillae.

NOTE.-The natural attitude of the head of a grasshopper is such that 
the labrum and labium appear to be fore and hind lips respectively; and the mandibles and maxillae, fore and hind pairs of jaws.

Each maxilla consists of four primary and two secondary parts. The primary parts are the cardo, stipes, lacinia, and palpifer; the secondary parts are the galea, and maxillary palpus.

'The labium consists of the submentum, mentum, ligula, two palpigers, and labial palpi.

PARTS OF THE THORAX.

(§ 47.) Division into segments.-The thorax consists of three segments. The cephalic or first segment is named the prothrax; the second or intermediate, the mesothorax; and the third or caudal, the metathorax.

These divisions of the thorax may be easily recognized by the appendages they bear. To the prothorax is articulated the first pair of legs; to the mesothorax are joined the second pair of legs and the first pair of wings ; and to the metathorax, the third pair of legs and the second pair of wings.

\section{PROTHORAX.}

(§ 48.) Dorsal Part (Pronotum). - That which may be properly termed the dorsal part of the prothorax is a large sunbonnet shaped piece which covers the greater portion of the sides as well as the dorsal surface of this segment. This piece is called the pronotum.

It is believed that the dorsal part of each thoracic segment consists typically of four sclerites. These are named, beginning with the cephalic, praescutum, scutum, scutellum, and postscutellum. These sclerites may be distinguished in the dorsal parts of the mesothorax and metathorax (mesonotum and metanotum) of many insects; but the pronotum consists usually of a single piece. In the insect which we are studying, although the pronotum consists of a single piece, it is crossed by three well marked sutures, indicating the division into four sclerites, which may be named as indicated above.

On the latero-dorsal aspect of the pronotum the suture 
between the praescutum and the scutum extends cephalad for a short distance and is then interrupted; the lateral portions of this suture is parallel with and quite near to the cephalic margin of the pronotum. Near the center of each lateral aspect of the pronotum there is a short cephalo-caudo-dorsal suture which separates the lateral fourth of the scutellum from the mesal part of that sclerite. None of the sutures extend to the lateral margin of the pronotum.

Make drawing of the lateral aspect of the pronotum.

(§ 49.) Ventral Part (Prosternum).- On the ventral surface of this segment between the legs there is a sclerite which bears a large tubercle; this is the sternum of the prothorax or prostermum.

( $\$$ 5.) Lateral Parts.-Owing to the great development of the pronotum, which covers the larger portion of the sides as well as the dorsal surface of the prothorax, the lateral parts of this segment are rudimentary. The following named sclerites, however, may be distinguished.

Epistcrmum.-Between the pronotum and the end of the lateral prolongation of the prosternum, which extends on each side of the segment cephalad of the leg, is a conspicuous triangular sclerite; this is the epistcrnum.

Fugular Scterites. - In the membrane connecting the prothorax with the head there is on each side, just cephalad of the dorsal corner of the episternum, a pair of sclerites. These were named by a French entomologist pièces. jugulaires. ${ }^{1}$ They may be called the jugular sclerites.

Note I.-The homology of these sclerites is not well understood. They were supposed by Straus-Durckheim to represent the remains of two distinct segments. But Newport ${ }^{2}$ beliered that they were detached portions of the prothorax; and suggested that they represent the paraptera of this segment.

NoTE II.-It is believed that each lateral part of each thoracic segment consists of three sclerites. These are named the episternum, the cpimeron, and the parapteron. In many cases not all of these parts can be dis-

1 Scra!s-Durckheim, Considération Générales sur l'Anatomie Comparée des Animaux Articuiés, p. 75 .

2 Article Insecta, Todd's Cycl. Anat. and Phys., p. $9 x$ r. 
tinguished. This may be due to the non-development of a part, or to the effacing of a suture between two parts. In the prothorax, paraptera have never been found unless, as suggested by Newport, the jugular sclerites represent these parts. In many insects the epincra of the prothorax can not be distinguished from the episterna, the suture on each side between these sclerites being obsolete. In the insect which we are studying, either this is the case or the epimera of this segment are not developed.

MESOTHORAX AND METATHORAX.

(§5I.) Union of these segments.-The second and third thoracic segments are firmly joined together, forming a box to which the two pairs of wings and the second and third pairs of legs are joined. Owing to the intimate union of these two segments it will be easier to describe them together than separately.

With fine pointed scissors cut away the caudal borders of the pronotum, that part which overlaps the mesonotum; be careful not to break the membrane connecting the prothorax and mesothorax.

\section{(\$52.) Dorsal Part (Mesonotum and metanotum).} -The dorsal part of the mesothorax is termed the the mesonotum, that of the metathorax, the metanotum. Unlike the pronotum these parts are confined to the dorsal aspect of the body. By cutting away the caudal part of the pronotum as indicated above and spreading the wings laterad, these parts are exposed. Each consists of a nearly square area. To the lateral margins of the mesonotum is articulated the first pair of wings; and to the lateral margins of the metanotum, the second pair of wings.

The sutures indicating the outlines of the sclerites, of which the mesonotum and metanotum are composed, are not all well defined; there is consequently some difficulty in determining the limits of the sclerites.

The following named parts may be distinguished in the mesonotum.

Scutellum.-On the dorsimeson near the center of the mesonotum is a shield shaped prominence; this is the scutellum of the mesothorax. 
Scutum.-Cephalad of the scutellum is a large sclerite to the lateral margins of which the first pair of wings is articulated; this is the scutum of the mesothorax.

Post-scutellum.-Caudad of the scutellum there is a sclerite which, like the scutum, extends from the base of the wing of one side to that of the other; this is the post-scutellum of the mesothorax.

NotE. - The three sclerites just named are all that can be easily determined; but in some specimens there may be detected by carcful examination a very narrow sclerite cephalad of the scutum: this is the praescutum of the mesothorax.

The structure of the metanotum is similar to that of the mesonotum.

Make drawing of these parts.

(§ 53.) Ventral Part (Mesosternum and Metastern$\mathrm{um})$.- On the ventral surface of the body between the legs of the second thoracic segment is a large sclerite; this is the sternum of the mesothorax or mesosternum. The cephalic margin of the mesosternum is nearly straight; the caudal margin, deeply notched by a large nearly square incision.

Caudad of the mesosternum there is a large sclerite, the mesal part of which is prolonged cephalad so as to accurately fit the notch in the caudal border of the mesosternum; this is the sternum of the metathorax or metasternum.

The caudal border of the metasternum is also notched; and the first abdominal segment is dove-tailed into it.

Make drawing of these parts.

(§54.) Lateral Parts (Episterna, Epimera, and Paraptera). - Examine one side of the second and third thoracic segments. Note that it is chiefly composed of four large sclerites, which extend from the fossae of the legs dorsocephalad. These sclerites are named as follows:

Epistermum of the mesothorax.-The first or cephalic of these four sclerites is the episternnm of the mesothorix. The sutures between the episterna and the mesostemum are only faintly indicated in this species. 
Epimeron of the mesothorax.-This is the second of this series of sclerites.

Episternum of the metathorax.-This is the third of this series of sclerites; it is the one which bears the oblique yellow band characteristic of this species.

Epineron of the metathorax.-This is the caudal member of this series of sclerites.

In addition to the four large sclerites just described, observe the following named parts:

Parapteron of the mesothorax.-Articulated to the dorsal extremity of the episternum of the mesothorax and cephalad of the base of the first wing is a small inconspicuous sclerite; this is the parapteron of the mesothorax.

Parapteron of the metathorax.-Articulated to the dorsal extremity of the episternum of the metathorax and cephalad of the base of the second wing is also a small inconspicuous sclerite; this is the parapteron of the mctathorax.

Spiracles and Peritremes.-Between the ventro-caudal angle of the epimeron of mesothorax and the fossa of the leg is an organ which consists of a slit-like opening guarded by two fleshy lips; this is one of the openings of the respiratory system ; these openings are called spiracles. When, as in this case, a spiracle is surrounded by a circular sclerite, such a sclerite is termed a peritreme.

In the membrane connecting the mesothorax with the prothorax there is on each side a spiracle. This spiracle is covered by the free margin of the pronotum. In this case the peritreme is developed on the ventral side of the spiracle into a prominent papilla.

Make drawing of lateral parts of mesothorax and metathorax.

( $\$ 55$.$) Review.- The thorax consists of three segments,$ which are named, beginning with the cephalic, prothorax, mesothorax, and matathorax.

The body wall of each of these seginents is believed to consist typically of eleven sclerites. Of these, four pertain to the dorsal 
part of the segment; three, to each lateral part; and one, to the ventral part.

The dorsal sclerites are named, beginning with the cephalic, praescutum, scutum, scutellum, and postscutellum.

Of the two principal lateral sclerites, the cephalo-ventral one is the epistermum, the caudo-dorsal one, the epimeron. The third lateral sclerite is small; is articulated to the episternum near the base of the wing; and is called the parapteron. Paraptera have not been found in the prothorax; but there has been found on each side, in the membrane connecting this segment with the head, a pair of sclerites termed the jugular sclerites.

The ventral sclerite is known as the stermum. The sterna of the three thoracic segments are designated as the prostermum, mesosternum and metusternum respectively.

The dorsal part of the body wall of each segment is called the tergum. This name is also applied to the dorsal part of the three thoracic segments collectively.

The tergum of the prothorax is frequently called the pronotum; the tergum of the mesothorax, the mesonotum; and that of the metathorax, the metanotum.

There are in this insect two pairs of thoracic spiracles.

APPENDAGES OF THE THORAX.

The appendages of the thorax are the legs and wings; the number and distribution of these have already been given.

(§56.) Legs.-Examine the ventral aspect of the first pair of legs. Each leg will be found to consist of the following named parts :

Coxa.-This is the proximal segment of the leg. It is subglobular in outline. Examine the cephalic aspect of the coxa; and note the longitudinal suture which traverses this side of it.

Trochanter.-This is the second segment of the leg; and is much smaller than the coxa. The ventral aspect of it is much longer than the dorsal. 
Femur.-This is the third and principal segment of the leg.

Tibia.-This is the fourth segment of the leg. It nearly equals the femur in length, but is more slender.

Tarsus.-The tarsus includes all of that part of the leg distad of the tibia. It consists in grasshoppers of three segments.

The last segment of the tarsus bears a pair of claws.

On the ventral surface of the tarsus there is a series of cushions; these are called pulvilli. The distal segment of the tarsus bears a single pulvillus which projects between the claws; this is often referred to in descriptive works as the pulvillus.

NotE.-In the membrane connecting the coxa with the thorax, just cephalad of the coxa, is a sclerite; this I believe to be the trochantin. The trochantin is a sclerite which is considered to be an appendage of the coxa; and it is stated by prominent writers that its normal position is between the coxa and the epimeron. But the position of the sclerite described here is between the coxa and the episternum.

Make drawing of one of the cephalic legs.

The same parts may be traced on each of the other legs.

(§ 57.) Wings.-The wings are plate-like or membraneous expansions of the body wall. Each wing is traversed by many linear thickened portions; these are termed veins, or nerves. The principal veins extend proximo-distad. These are joined together by many smaller veins or veinlets. The thin parts circumscribed by the veins and veinlets are called cells or areolets.

NoTE. - In nearly all of the orders of insects the principal veins of the wings have been named, as they present valuable characters for separating genera and larger groups. But as I know of no author who has used the venation of the wings in describing grasshoppers, it does not seem worth while, therefore, to attempt to trace the homologies of the reins of the wings of these insects; especially as the specialists in each of the other orders use a peculiar nomenclature.

The two pairs of wings of the grasshopper differ remarkably in form and texture.

Mesothoracic Wings ( Tegmina).-The mesothoracic wings are long narrow, and of a parchment like texture. They are termed tegmina. They are also frequently designated as wing-covers.

Metathoracic Wings.-The metathoracic wings are much larger and of more delicate texture than the first pair of wings. When not 
in use they are folded in plaits like a fan and concealed by the tegmina. Some writers who designate the mesothoracic wings as tegmina or wing covers, describe the metathoracic wings simply as the wings.

Make diagrams showing the outline of one of the wings of each pair. Do not attempt to represent the veins and veinlets; as the time necessary to do this well can be spent more profitably.

NOTE. - If a student wishes to study the venation of the wings of grasshoppers, it will be best for him to wait until he has become familiar with more simple forms of venation.

\section{PARTS OF THE ABDOMEN.}

( $\$ 5^{8 .}$ ) Number of segments.-There is a difference of opinion as to the number of segments in the body of the grasshopper. The difficulty arises from the complexity of the caudal end of this region; and the fact that some authors have considered the first abdominal sternum as a part of the metathorax. Eight abdominal segments can be readily distinguished in the female; and nine in the male. ${ }^{1}$ Caudad of the eighth abdominal segment of the female and the ninth of the male are a number of sclerites which are considered by some writers to be merely appendages of the abdomen; other writers hold that certain of these sclerites represent sterna, and certain others, terga. Thus while one writer ${ }^{2}$ states that: "The inferior surface of the abdomen in the males consists of eight, lut only of seven segments in females"; another ${ }^{3}$ describes ten in each sex; and still another "describes eleven in each sex.

It is not within the scope of this work to enter into any discussion of the matter. I shall describe the parts as if there were eleven segments; but wish the student to understand that the socalled eleventh segment may be merely an appendage of the

1 See $\oint_{21}$ for sexual characters.

2 Westwood, Classification of Insects I, p. 457.

8 Packand, Zoology, p. 328.

4 Brooks, Outline for 'Teachers' Class. 
tenth; and that what is described here as the ninth and tenth segments have not been considered as such by certain very high authorities.

(§ 59.) First Abdominal Segment. - The dorsal and ventral parts of the first abdominal segment are widely separated by the caudal part of the cavities for the insertion of the third pair of legs.

The ventral part of this segment is dove-tailed into the metasternum, and at first sight would be taken for a part of the thorax.

On each side, in the dorso-lateral part of this segment, there is a large opening which is closed by a very delicate membrane; these are the auditory organs; the membrane is the tympanum.

Just cephalad of each auditory organ there is a small opening; these are the first pair of abdominal spiracles.

(§6o.) Second to Eighth Abdominal Segments.Each of the abdominal segments, from the second to the eighth inclusive, is ring like in form, and without appendages.

In each of these segments the lateral margins of the tergum join the pleura ${ }^{1}$ without any suture. Near the cephalo-ventral angle of each pleurum there is a spiracle. The sterna are well developed and are separated from the pleura by a narrow involuted membraneous part.

(§ 6r.) Caudal Part of Abdomen of Female.-The most prominent portion of the caudal part of the abdomen of the female is the ovipositor. This is an organ consisting of four strong, curved, and pointed pieces which form the most caudal part of the body. With this organ the insect makes a hole in the ground in which she lays her eggs. This is done by alternately bringing together and separating the two pairs (dorsal and ventral) of pieces, and at the same time pushing the body into

\footnotetext{
1 The lateral part of a segment is termed the pleurum; in the same way that the ventral part is called the sternum; and the dorsal part, the tergum. By some writers the entire dorsal part of an insect is called the tergum; the lateral part, the pleurum; and the ventral part, the sternum. These writers apply the terms tergite, pleurite, and sternite respectively to the dorsal, lateral, and sternal regions of each segment.
} 
the ground. Examine carefully these pieces; and note how well they are adapted to this purpose.

Between the ventral pieces is the opening of the oviduct.

Ventrad of this opening and also between the ventral pieces of the ovipositor is a pointed prolongation of the eighth abdominal sternum; this has been termed the egg guide. Dorsad of the egg guide there is a forked organ which probably is used also in placing the eggs.

The ventral pieces of the ovipositior are supported by two pairs of sclerites; there being a sclerite closely applied to the ventral surface of each pair, and one to the lateral surface of each.

The ninth and tenth abdominal terga are shorter than any of the preceding abdominal terga and are joined together on each side, the lateral parts of the suture separating them being obsolete.

Caudad of the tenth tergum there is on the dorsimeson a shield shaped piece; this is believed to represent an eleventh segment. It consists of two sclerites; as is indicated by a transverse suture.

On each side, projecting from beneath the caudal border of the tenth tergum, is a pointed appendage; these are the cerci.

Entad of each cercus there is a much larger triangular sclerite, which extends from the lateral border of the tenth tergum to the caudal apex of the eleventh tergum; these are termed by Brooks the podical plates; by Packard the uropatagium.

By lifting the free end of the eleventh segment the caudal opening of the alimentary canal, the amus, is exposed; it is situated between the podical plates.

Caudad of the podical plate is the dorsal pair of pieces of the ovipositor.

Make drawings of dorsal and lateral aspects of this part of the body.

(\$62.) Caudal Part of the Abdomen of the male.- 
In the male ten abdominal sterna are present; the tenth is a hood shaped sclerite on the pseudo-caudal aspect of the body.

As in the female, the ninth and tenth abdominal terga are united on their lateral margins.

Projecting from the caudal margin of the tenth tergum there is on the dorsimeson a forked appendage, the furcula.

The eleventh tergum is furrowed by three deep longitudinal grooves.

The cerci are situated as in the female but are longer.

The podical plates are nearly as in the female.

Make drawings of dorsal and lateral aspects of this part of the borlv 

